\title{
Rapid field evaluation of drip and microspray distribution uniformity
}

\author{
CHARLES M. BURT \\ BioResource and Agriculture Engineering Department and Irrigation Training and Research \\ Center, California Polytechnic State University, San Luis Obispo, CA 93407, USA
}

\begin{abstract}
The Cal Poly ITRC irrigation evaluation programs have been widely used to assess the global distribution uniformity (DU) of drip and microsprayer irrigation systems. The field procedures and formulas used in the program are presented in this paper. The system DU is estimated by mathematically combining the component DU values. DU components include pressure differences, "other causes" (such as manufacturing variation, plugging, and wear), unequal drainage, and unequal application rates. Results are presented from evaluations by several entities, including Cal Poly ITRC. Cal Poly evaluations of 329 fields provided an average $\mathrm{DU}_{\mathrm{lq}}$ of 0.85 for drip and 0.80 for microspray. Approximately $45 \%$ of the non-uniformity was due to pressure differences, $52 \%$ was due to "other causes", $1 \%$ due to unequal drainage, and $2 \%$ due to unequal application rates. The data show that with good design and management, it is possible to have high system DU values for at least a 20 -year system life.
\end{abstract}

Key words: distribution uniformity (DU), drip irrigation, efficiency, evaluation, irrigation, microirrigation, microspray, plugging, trickle

\section{Background}

The past 30 years have seen several important developments in irrigation system use in California. Drip irrigation (a.k.a. "trickle" or "low volume") systems for trees and vines became popular in California in the mid-1970s. In the early 1980s, microsprayer systems replaced many of the drip systems on trees, as growers became convinced that the larger soil wetted volume under microsprayers (hereafter called "micro" in this paper) was beneficial to crop growth-especially for citrus and avocado trees. In the late 1980s, subsurface drip irrigation (SDI) on row crops also became popular in some areas; however, by the late 1990s, many of the row crop SDI users had converted to above ground tape because above ground systems had more predictable soil wetting patterns, fewer root intrusion problems, and were generally easier and less expensive to own and operate. The history of drip/micro irrigation is described in detail by Burt \& Styles (1999). 
Evaluation procedures on drip/micro systems have evolved as well. In the 1970s it became obvious that both design and maintenance influence the distribution uniformity (DU) of water in drip/micro systems. Furthermore, it was evident that there was a wide range of DUs to be found among drip/micro systems. Efforts to evaluate field DU began and were stimulated by a variety of reasons including theoretical academic interest, desires to pinpoint maintenance problems in specific fields, the need to know DU to properly compute applied gross water depths, and verification of a new irrigation system's stated performance.

Published in 1956, USDA Agriculture Handbook 82 defined procedures for evaluating furrow, border, and hand move sprinkler irrigation methods. In Handbook 82, the mathematical description of uniformity was different for each irrigation method. However, the handbook did introduce the concept of using the "average of the low $\frac{1}{4}$ " as the numerator in a uniformity ratio that described overlap patterns with hand move sprinklers. This concept was later incorporated into the "Low Quarter Distribution Uniformity" (DU $\left.\mathrm{lq}_{\mathrm{lq}}\right)$ definition that is commonly used today (Burt et al., 1997).

Merriam et al. (1973) developed one of the first field evaluation techniques for drip irrigation systems. Their evaluation procedure required collecting data about soil type, available moisture, irrigation scheduling, percent soil wetted volume, and pipe materials. Emitter flow rates were measured at four plant locations along each of four hoses on one manifold. If each plant had four emitters, a total of 64 measurements were taken. The $\mathrm{DU}_{\mathrm{lq}}$ calculation (called "Emission Uniformity", or "EU" by the authors) was calculated using the average of the lowest 16 rates $\left(q_{\min 1 q}\right)$ and the average of all 64 rates $\left(q_{\text {avg }}\right)$. An adjustment was made for the number of emitters per plant $(n)$. Although pressures were measured, they were not incorporated into the $\mathrm{DU}_{\mathrm{lq}}$ computation. The final $\mathrm{DU}_{\mathrm{lq}}$ value was computed as:

$$
\mathrm{DU}_{\mathrm{lq}}=\left(1-\frac{1}{\sqrt{n}}+\frac{1}{\sqrt{n}} \cdot \frac{q_{\mathrm{min} \mathrm{lq}}}{q_{\mathrm{avg}}}\right) \times 100
$$

Karmeli \& Keller (1974) considered two components of non-uniformity in the design of a drip/micro system: manufacturing variation and pressure differences. It should be noted that this formula was intended for the design, not evaluation, of an irrigation system. Their recommendation for a new DU equation was:

$$
\mathrm{DU}_{\mathrm{lq}}=\left(1-1.27 \frac{\mathrm{cv}_{\mathrm{m}}}{\sqrt{n}}\right) \times\left(\frac{q_{\text {min lq }}}{q_{\mathrm{avg}}}\right) \times 100
$$

where $\mathrm{cv}_{\mathrm{m}}$ is the manufacturing coefficient of variation (standard deviation divided by the mean) of emitter flow rates, $q_{\mathrm{min} \text { lq }} / q_{\text {avg }}$ is the ratio of "minimum" to average flow rates due to pressure differences. 
Written another way, this early formulation of a combined DU can be written as:

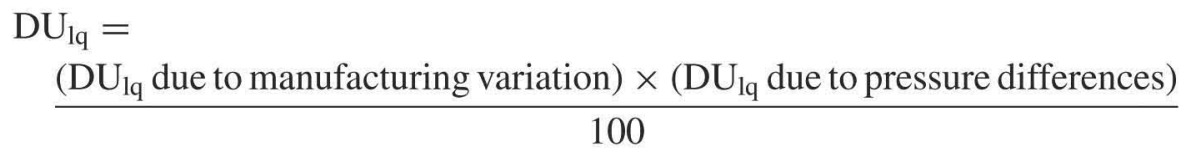

Bliesner (1977) recognized the importance of being able to isolate causes of non-uniformity through a field evaluation. He recognized that pressures must be adjusted by the emitter discharge exponent, $x$, found in the emitter discharge equation. The emitter discharge equation is:

$$
q=k P^{x}
$$

where $q$ is the emitter flow rate, $k$ a constant that depends upon the emitter path size and units of flow rate and pressure, $P$ the pressure, $x$ the emitter discharge exponent.

With Bliesner's procedure, the exponent $(x)$ value was determined by taking a number of pressure and discharge measurements throughout the field, and developing a field emitter discharge equation. Bliesner introduced the concept of "pressure uniformity" which was eventually used as:

$$
\mathrm{DU}_{\mathrm{lq}} \text { due to pressure }=\left(\frac{\text { average of low } 1 / 4 \text { of } P \text { measurements }}{\text { average of all } P \text { measurements }}\right)^{x} \times 100
$$

This pressure DU component was used in a complex formula that incorporated flow rate measurements to provide a final estimate of DU.

Merriam \& Keller (1978) revised their 1973 procedure and incorporated pressure measurements and the discharge exponent $(x)$ into the final $\mathrm{DU}_{\mathrm{lq}}$ estimate.

The final DU computation was as follows:

$$
\begin{aligned}
\mathrm{DU}_{\mathrm{lq}}= & \left(\mathrm{DU}_{\mathrm{lq}} \text { of flow rates }\right) \\
& \times\left(\frac{\text { minimum hose inlet } P \text { along the selected manifold }}{\text { averaged manifold minimum hose inlet } P}\right)^{x}
\end{aligned}
$$

The 1978 procedure did not adjust for the number of emitters per plant, and no procedure was defined for determining the emitter discharge exponent.

Since the 1970s there have been many mathematical analyses of hypothetical situations to help explain evaluation principles. Solomon \& Keller (1978) examined the hydraulics of hypothetical laterals and concluded that a system's manufacturing variation was as important a design consideration as pressure differences. Nakayama et al. (1979) noted that it was important to have evaluation techniques that provided comparable DU values, regardless 
of the irrigation method. Their work assumed a normal distribution of flow rates, and examined the impact on DU of the number of emitters per plant and the manufacturing coefficient of variation. Bralts \& Kesner (1983) also assumed a normal distribution of flow rates and recommended that with 18 flow rate measurements in a subunit, a statistical uniformity coefficient could be accurately estimated. A proposed ASAE "Field Evaluation of Microirrigation Systems, EP-458" (Lamm et al., 1997) drew heavily from the statistical work with hypothetical flow rates.

Nakayama \& Bucks (1981) wrote one of the first peer reviewed papers that recognized the need to develop evaluation procedures to account for emitter clogging. They performed a theoretical examination of how clogging would impact system uniformity, assuming a random distribution of clogging problems throughout a field. They acknowledged that their analysis did not account for partial clogging of emitters, nor did it account for a non-uniform pattern of clogging throughout a field.

\section{Early field evaluations of drip/micro systems}

California field evaluations of drip/micro systems in the late 1970s and early 1980s were done with a wide variety of techniques. Although there had been several professional papers published on the theory of distribution uniformity, the only widely available field evaluation procedure was that of Merriam \& Keller (1978). Handley et al. (1983) published results of evaluations of 112 drip/micro systems on 40 ranches in the southern San Joaquin Valley performed in 1981. The evaluations were done with the Merriam \& Keller (1978) procedure. Their results are seen in Table 1.

Fry (1985) reported the results (Table 2) of 57 field drip evaluations in the San Joaquin Valley of California. He utilized a modified Merriam \& Keller (1978) approach that incorporated a prediction of flows at individual emitters throughout the system using the emitter discharge characteristics, predicted friction losses and pressures in lateral lines, and minimum lateral inlet pressures.

In the early 1980s, the Water Conservation Office of the California Department of Water Resources (DWR) began to fund "mobile laboratories" such as the one described by Fry (1985). The mobile labs were typically composed of two-person teams that were provided some logistical support by an irrigation or resource conservation district. Simultaneously, various university extension offices and Soil Conservation Service (now NRCS/USDA) offices began attempts to perform irrigation evaluations.

It was soon apparent that each team customized its own evaluation procedure. Some followed the Merriam and Keller approach, but even those teams differed in techniques and definitions. Other teams developed completely new 
Table 1. Results from Handley et al. (1983) evaluations using Merriam and Keller (1978) procedures (approximation).

\begin{tabular}{lc}
\hline Uniformity $(\%)$ & $\begin{array}{c}\text { Percent of } \\
112 \text { systems }\end{array}$ \\
\hline$>95$ & 2 \\
$0-95$ & 18 \\
$85-89.9$ & 28 \\
$80-84.9$ & 12 \\
$75-79.9$ & 18 \\
$70-74.9$ & 5 \\
$65-69.9$ & 1 \\
$60-64.9$ & 4 \\
Less than 60 & 12 \\
Total & 100 \\
Average uniformity & $79 \%$ \\
\hline
\end{tabular}

Table 2. Results of Fry (1985) drip evaluations.

\begin{tabular}{ll}
\hline Range of EU & Number of fields \\
\hline $90-100$ & 10 \\
$70-89$ & 35 \\
Less than 70\% & $\underline{12}$ \\
Total & 57 \\
\hline
\end{tabular}

procedures-often based on incorrect assumptions. By 1983, if three mobile labs were to evaluate the same field, they may have obtained DU or EU values of 65,70 , and $80 \%$. Furthermore, some teams spent several days in a field and other teams spent only a few hours.

\section{Key ingredients of the Cal Poly ITRC drip/micro evaluation procedure}

In an effort to standardize procedures and results, the California State Water Resources Control Board funded a project in the then-Agricultural Engineering Department of California Polytechnic State University (Cal Poly), San Luis Obispo, to develop improved techniques of irrigation system evaluation for all irrigation methods. Those techniques were to be adapted by all DWR-funded mobile labs, and were published by Burt et al. (1985) in a 
handbook. A training course on evaluation procedures was begun in 1985 that stressed concepts, field sampling techniques, and use of the software programs for data organization and computations. The Irrigation Training and Research Center (ITRC) at Cal Poly has provided the short courses about twice annually since that time, continuously upgrading and expanding the software and evaluation procedures. Approximately 800 persons have been trained in the evaluation short courses, and the software is widely used throughout the western US.

An M.S. thesis by Dahlgren (1987) examined three different drip/micro fields in detail to compare the relatively quick ITRC evaluation procedure DU against a much more detailed process. He concluded that the sampling and computation approaches were sound, but made several recommendations for improvement, which were incorporated into the ITRC program. However, the basic ingredients of the drip/micro evaluation procedures remain unchanged, and the DU for a field would be approximately the same whether evaluated with either the 1987 or the 2003 procedures (date of the last major update). Key concepts embedded in the drip/micro evaluation procedure are listed below.

\section{Global or system DU}

Evaluation procedures for all irrigation methods must encompass all components of uniformity for the complete system across the whole field, rather than only a few components in a small area of the field. Measurements must be taken across an entire field rather than only along a single manifold. The basic question in DU evaluation is this: How evenly do plants throughout the entire field receive water? The answer must therefore include factors such as inequitable scheduling and unequal drainage of hoses/pipes during startup and shutdown.

\section{DU components}

Every irrigation method has numerous DU components, or factors that influence the overall system DU. Each component contributes to the nonuniformity of the total system. Therefore, if one component is ignored in an evaluation procedure, the system DU will be over-estimated. The specific components that are considered in the ITRC program for drip/micro systems are:

1. Pressure differences. Pressure differences between emitters will cause flow rate differences as described by the relationship $q=k P^{x}$.

2. Uneven spacing. This refers to non-uniformity that is caused by having a different number of emitters per unit area in the field. This is typically caused by having two or more different plant spacings, but with the 
same number of emitters per plant. Different spacing can be properly compensated for by applying water in different zones for different durations. This DU component is not a factor for most fields, but it is extremely important in enough fields that it is included in the evaluation procedure.

3. Unequal drainage. When a drip/micro system is shut off (or a block is shut off), some emitters may continue to drain for a considerable length of time after most of the emitters have stopped discharging water. This is particularly important on sloping ground for systems that have irrigation sets of very short durations (e.g., for systems that use "pulsing"). In flat topography with long set durations ( $8-24 \mathrm{~h}$ ), this DU component has almost no impact on the final system DU value.

4. "Other". This refers to any factor that would cause flow rate differences among emitters even though the emitters are all at the same pressure. Such factors include plugging (by minerals, dirt, insects, etc.), wear (such as occurs with heavy applications of gypsum through microsprayers), and manufacturing variation. Although early research gave special attention to manufacturing variation (manufacturing coefficients of variation of $0.05-0.50$ were considered by Nakayama et al., 1979), the impact of poor manufacturing quality has declined drastically in the last decade. Typical manufacturing $\mathrm{cv}$ values today are in the $0.02-0.06$ range.

The evaluation procedure does not quantify flow rate differences in subsurface drip irrigation (SDI) caused by soil texture differences (Burt \& Styles 1999), because those differences are extremely difficult, if not impossible, to measure in the field. Also, the flow rates of shallow buried $(15-23 \mathrm{~cm})$ irrigation tapes (which represent the majority of SDI acreage) do not appear to be significantly impacted by the surrounding soil (Raphael, 1993). Likewise, the effect of temperature differences between emitters is ignored because very few emitters now have the long smooth paths that were at one time particularly sensitive to temperature differences (Parchomchuk, 1976).

\section{Combining DU components}

The system DU is computed as a product of the component DU values. The system DU is never directly measured. There are several reasons for this. First, if one simply measures all the flow rates throughout a field one cannot determine whether the flow rate differences are due to pressure differences, or due to "other" causes such as plugging, wear, and manufacturing variation. Second, several DU components for drip/micro cannot be evaluated by simply measuring flow rates. 
For drip/micro,

$$
\begin{aligned}
\text { system } \mathrm{DU}_{\mathrm{lq}}= & \text { pressure difference } \mathrm{DU}_{\mathrm{lq}} \times \text { uneven spacing } \mathrm{DU}_{\mathrm{lq}} \\
& \times \text { unequal drainage } \mathrm{DU}_{\mathrm{lq}} \times \text { "Other" } \mathrm{DU}_{\mathrm{lq}}
\end{aligned}
$$

where all the $\mathrm{DU}_{\mathrm{lq}}$ values are expressed as values between 0 and 1.0, rather than as percentages.

Following ASCE convention, the DU value is now expressed as a fraction rather than as a percentage so that there is less confusion between the DU term and various efficiency terms that are typically expressed as percentages (Burt et al., 1997).

The formulation of system DU as a product of DU components was first introduced by Karmeli and Keller, as noted earlier. It was utilized in the ITRC procedures because it enables the software to identify the relative importance of each component for every evaluation. Evaluators can then target specific actions that a farmer might best take to improve the system DU because they know the relative impact of each action upon the system DU.

There is uncertainty regarding the best procedure to use in combining the DU components. Clemmens \& Solomon (1997) provided a review of various combination procedures (including the simple multiplication procedure currently used by ITRC). They recommended the following formula to combine components:

$$
\begin{aligned}
& \mathrm{DU}_{\mathrm{lq}} \approx \\
& 1-\sqrt{\left(1-\mathrm{DU}_{\mathrm{lq} 1}\right)^{2}+\left(1-\mathrm{DU}_{\mathrm{lq} 2}\right)^{2}+\frac{\left(1-\mathrm{DU}_{\mathrm{lq} 1}\right)^{2}\left(1-\mathrm{DU}_{\mathrm{lq} 2}\right)^{2}}{K_{\mathrm{a}}^{2}}}
\end{aligned}
$$

where $\mathrm{DU}_{1}$ and $\mathrm{DU}_{2}$ are components of $\mathrm{DU}$ (e.g., pressure differences, or "other" as noted earlier), and $K_{\mathrm{a}}$ is a factor (typical value $=1.27$ ) that depends upon the type of data distribution.

Clemmens \& Solomon (1997) clearly showed that the ITRC multiplication procedure gives a lower DU value than does their recommended formula, above. However, the author is unconvinced that their DU computation approach uses the proper assumptions regarding data distribution and interdependence. Dahlgren (1987) did show (Table 3) that a DU computed from systematic flow rate measurements throughout a field was slightly higher than a DU computed by multiplication of components. But Dahgren's data was obtained with a sampling procedure that was subsequently improved. His differences may have been due to data collection, rather than due to how the components were combined. 
Table 3. DU results from Dahlgren (1987).

\begin{tabular}{lll}
\hline Field number & Systematic DU & $\begin{array}{l}\text { DU computed by multiplication of components } \\
\text { (using older data sampling techniques) }\end{array}$ \\
\hline 1 & .93 & .89 \\
2 & .83 & .77 \\
3 & .64 & .57 \\
\hline
\end{tabular}

For persons interested in pursuing this topic, the field data and computed DU components of approximately $400 \mathrm{drip} /$ micro evaluations are available on the ITRC web site (www.itrc.org). The author also plans to conduct detailed systematic flow rate and pressure sampling in four different drip/micro fields before the end of 2004. The fields will represent different conditions of topography and pressure regulation. The data will be used to compare ITRC's present multiplication procedure against other mathematical procedures of combining DU components. Results will be made available on ITRC's web site.

\section{The "Element" concept}

An element is defined as the smallest area in the field that requires water, but within which the variation of distributed water is not important (Burt et al., 1997). In orchards and vineyards, a $D_{\mathrm{lq}}$ of 1.0 would not imply that every square meter of the field received the same depth of water, but that each plant received the same depth. The term "depth" is used rather than "volume" since different areas of the field may have different plant spacings. The low-quarter distribution uniformity, $\mathrm{DU}_{\mathrm{lq}}$, is therefore defined as:

$$
\mathrm{DU}_{\mathrm{lq}}=\frac{\text { average low quarter depth }}{\text { average depth of water accumulated in all elements }}
$$

\section{DU, not EU}

Early work on describing uniformity of drip/micro systems used the term "emission uniformity (EU)". ITRC utilizes the DU $\mathrm{lq}_{\mathrm{lq}}$ term because:

1. In many cases, the term EU only referred to the uniformity of emitters on a single hose when it was new. This means it was not a system uniformity measure, and only accounted for manufacturing variation and pressure differences. This error is particularly prevalent because manufacturers have 
hose hydraulics programs that analyze a single hose, and therefore can only report the DU of that single hose. Also, people frequently refer to the formula for EU by Karmeli \& Keller (1974), but that formula was intended for design, not for system evaluation.

2. If uniformity is properly measured for a complete system, the same uniformity definition should be applicable for furrow, drip, and sprinkler systems. EU was reserved only for drip/micro systems.

3. EU, by its very definition, does not account for factors such as unequal drainage and uneven spacing.

\section{DU comparison among methods}

If $\mathrm{DU}_{\mathrm{lq}}$ is properly evaluated for any irrigation method (furrow, sprinkler, drip, etc.), it will give a DU value that can be compared against any other method. The basic definition of DU is the same for all methods. The only differences lie in what components impact DU, and how to measure those components. For example, with hand move sprinklers on field crops, the sprinkler overlap pattern DU is very important, but it is not measured for drip/micro or furrow for obvious reasons. The ITRC evaluation procedures for all methods (not only drip/micro) attempt to account for all components, and therefore give comparable results.

\section{Data collection and computation of DU component values}

The details of data collection and $\mathrm{DU}_{\mathrm{lq}}$ computations are crucial to understanding any evaluation procedure. These details are explained in the sections below.

\section{$D_{\mathrm{lq}}$ related to pressure differences $\left(\mathrm{DU}_{\mathrm{lq} \Delta \mathrm{P}}\right)$}

The evaluator must be able to determine the variation in emitter pressures throughout the field. But more importantly, for giving recommendations to the farmer for system improvement, it must be known where the pressure differences occur in the hydraulic system. For example, there is very little that can be done to minimize pressure differences along hoses, but there are relatively simple options to minimize pressure differences between hose inlets or between block inlets. The pressure measurement locations are designed to be able to compare: 
1. Pressures along individual hoses. Three pressure measurements are made along each hose that is selected:

- head of the hose,

- halfway down the hose,

- distant (hydraulic) end of the hose.

One could argue that more than $75 \%$ of the friction of the hose occurs at the midpoint of the hose. However, if one considers the wide range of topography encountered along drip/micro hoses, and the tremendous range of pressure distribution patterns that result, then the middle of the hose is a reasonable location for a pressure measurement.

If a hose is fed in two directions from a manifold, then a total of five pressures are measured-the three listed above for the downhill hose, plus at the midpoint and far end of the uphill hose.

2. Pressures between individual hoses along a single manifold. The criteria for these define which hoses are measured for (1) above. The criterion is to take measurements on the closest hose to the inlet of the manifold and the most distant hose from the inlet of the manifold — for a total of two hoses per manifold.

3. Pressures at the head of each manifold. The criteria for these define which manifolds are selected. Six manifolds are selected, including the one closest to and most distant from the pump.

The total number of pressures that should be measured is 36 or 60 , depending upon whether hoses go in one or two directions from the manifold. Many systems have only one or two manifolds. In those cases, evaluators are still told to take the full complement of measurements (36 or 60). The summarized program output only distinguishes between pressure differences along hoses, and between hoses (it does not distinguish between pressure differences along manifolds versus between manifolds, although the data clearly show any trends). The computation of $\mathrm{DU}_{\mathrm{lq} \Delta P}$ uses the pressure measurements without any adjustment for location.

The $\mathrm{DU}_{\mathrm{lq} \Delta P}$ is calculated as:

$$
\mathrm{DU}_{\mathrm{lq} \Delta P}=\left(\frac{\text { average of the lowest quarter of the estimated flows }}{\text { average of all the estimated flows }}\right)
$$

where an "estimated flow" is not an actual estimated flow rate, but equals $P^{x}$. That is, every emitter pressure is adjusted by the discharge exponent, " $x$ ". The determination of the discharge exponent " $x$ " is as described below. 
The discharge exponent " $x$ " is computed from measurements of individual flow rates from a group of 16 emitters. These 16 emitters must be from a location near the beginning of the field (close to the pump and filters), and must all be at the same pressure. For some systems with high flow rates and/or large topography changes along hoses, the 16 emitters may be selected as four emitters from each of four hoses. The beginning of the field is designated because typically there are fewer plugging problems near the beginning of the field than at the ends of hoses. The pressure differences between emitters near the end of a hose should be less than in the middle of the hose, but because there tends to be more plugging at the hose ends, the middle of the hose is selected.

Once the 16 emitters have been selected, the individual emitter flow rates are measured at two pressures. If the average emitter pressure is $16 \mathrm{psi}$, it is recommended that pressures of 16 and 8 psi be used. The two pressures should be sufficiently different to give reasonably accurate results, and it is easier to drop the hose pressures than it is to raise them. The emitter discharge exponent is then computed as:

$$
x=\frac{\log (\text { average low flow rate/average high flow rate })}{\log (\text { low pressure/high pressure })}
$$

In recent years, most of the irrigation industry has evolved to using just a few emitter path designs. These are pressure compensating, orifice, and tortuous path designs. The discharge exponent $(x)$ for a simple orifice is 0.5 , and a typical discharge exponent for a molded tortuous path design is also about 0.5 . Evaluators are told that if they encounter one of these two types of emitters, they should input low pressure flow rates that correspond to an exponent of 0.5 -effectively "dry lab" values. A true exponent value would contain more error, due to the inaccuracies of typical pressure gauges, timing, and other measurements in the field, than a simple assumption of $x=0.5$.

\section{$\mathrm{DU}_{\mathrm{lq}}$ related to “Other" causes $\left(\mathrm{DU}_{\mathrm{lqO} O \mathrm{ther}}\right)$}

"Other" causes of non-uniformity include anything other than pressure differences that would cause a flow rate difference between emitters. In the field, it is impractical to quantitatively distinguish between the effects of clogging, wear, and manufacturing variation. It is possible to distinguish qualitatively through observation of cut-apart emitters and the type of filtration, questions about chemical injection, and observation of what flushes out from hose ends and for how long.

The $\mathrm{DU}_{\mathrm{lqO} \text { ther }}$ computation requires emitter flow rates from three locations in the field. At each location, there must be no pressure difference between 
the individual emitters. The pressures can be different at each location. These three locations are:

1. The middle of a hose in an area of the field that is estimated to have the "cleanest" emitters. This is generally on a hose that is hydraulically close to the water source. Individual flow rates are taken from 16 emitters. This is the location of the two pressure/flow tests that are needed to determine the emitter discharge exponent (described previously).

2. The middle of a hose in the middle of a manifold that is near the middle of the field. This might be considered to be a "typical" location. Individual flow rates are taken from 16 emitters, and the pressure is measured.

3. The end of a hose at the end of the most distant manifold. This is typically the dirtiest point in the field. Because of the larger variation in flow rates between emitters in this location, the sample size must be larger-28 emitters rather than 16. The pressure is also measured.

The $\mathrm{DU}_{\mathrm{lqO}}$ iner is then computed as:

$$
\mathrm{DU}_{\mathrm{lqOther}}=1-\frac{1}{\sqrt{n}}\left(1-\operatorname{average} \frac{q_{\mathrm{minlq}}}{q_{\mathrm{avg}}}\right)
$$

where $n$ is the number of emitters per plant,

$$
\text { average } \frac{q_{\text {min }}}{q_{\text {avg }}}=\left(\sum_{1}^{3} \frac{q_{\text {min }}}{q_{\text {avg }}}\right) / 3
$$

where $q_{\min }$ is the average of the lowest quarter flow rates from one of the sample locations (the average of four or seven measurements, depending upon the location), $q_{\text {avg }}$ the average of all the flow rates from one of the three sample locations (the average of 16 or 28 measurements, depending upon the location).

The $\mathrm{DU}_{\mathrm{lqO} \text { other }}$ is adjusted for $1 / \sqrt{n}$, as proposed by Merriam et al. (1973), to account for the averaging effect on manufacturing variation if several emitters are used per tree. When developing the algorithms in the evaluation software, the author debated as to whether or not it was appropriate to include the $1 / \sqrt{n}$ adjustment. Manufacturing variation and material aging should be distributed evenly across a field, so it is logical to use the $1 / \sqrt{n}$ adjustment for those subcomponents. However, wear and plugging are often not distributed evenly across a field, so there is some question as to whether the adjustment applied to these subcomponents. Certainly, a portion of the wear and plugging effects are "evened out" with multiple emitters per plant. In the end, it was decided 
that the most reasonable approach would be to apply the $1 / \sqrt{n}$ adjustment to the "other" causes category.

One might also wonder why the manufacturing variation component of DU is not isolated. After all, most manufacturers publish $\mathrm{cv}$ values for new emitters. In the ITRC programs the manufacturing $\mathrm{cv}$ is embedded among the "other" causes of non-uniformity because:

1. Evaluators often do not have access to published manufacturing cv values of particular models.

2. Many models are old and it is impossible to obtain their manufacturing $\mathrm{cv}$ values. The companies may no longer exist, and the dates of manufacture are unknown.

3. ITRC has noticed that in some cases the published manufacturing $\mathrm{cv}$ is less (i.e., the manufacturers report a better quality) than what a grower receives.

4. Manufacturing cv values can be pressure-dependent for some emitter models. The pressures in the field may not correspond to the laboratory test pressures.

\section{Uneven spacing DU}

The data needed for this computation include:

1. The area of the field with each tree or emitter spacing.

2. Plant spacings in each area.

3. Emitter spacing in each area.

4. Average emitter flow rate in each area.

5. Hours of emitter operation per week in each area.

Most systems have an uneven spacing DU $=1.0$. In the event that there are differences in the field, the computation is:

$$
\text { uneven spacing DU }=\frac{\text { lowest weekly depth applied }}{\text { average weekly weighted depth applied }}
$$

where lowest weekly depth applied refers to the application depth in the area that receives the least amount of water, average weighted depth applied refers to the average depth applied to the whole field in a week.

The program accepts input for up to three different areas in the field that have different plant/emitter spacing combinations. The uneven spacing DU computation certainly does not provide an exact " $\mathrm{DU}_{\mathrm{lq}}$ " computation. If there are only two areas, there is insufficient data for a "low quarter" value. 
Therefore, this DU component is a ratio of the absolute minimum to the average. Because uneven spacing is not a major DU component on most fields, this does not appreciably skew the results that are reported in this paper. In spite of its numerical inaccuracy, it does provide valuable information to a farmer who may not even be aware that such a non-uniformity exists in a field.

\section{Unequal drainage DU}

This is another DU component that typically has minimal impact upon the field DU. However, unequal drainage is often a noticeable problem on the downhill edges of fields. If it is identified, solutions can be applied, such as using longer set durations or installing special spring-loaded check valves at the lateral inlets. As with the uneven spacing DU, this is really not a "low quarter" DU. The data for this computation consist of a simple observation of how long some emitters continue to drain after most of the emitters have stopped draining, compared to the average emitter operation duration. Its relatively small impact on the overall system DU does not warrant more data collection time.

$$
\begin{aligned}
& \text { unequal drainage DU } \\
& \begin{array}{l}
=1-\left(\frac{\text { extra minutes of operation of some emitters }}{\text { average set duration, minutes }}\right) \\
\quad \times \text { fraction of the field with unequal drainage }
\end{array}
\end{aligned}
$$

\section{Different emitter models in the same field}

If the locations of different emitter models are systematic (the same number of different types of emitters per tree throughout the field), having two different emitter models in the same field will not cause non-uniformity between plants. For example, it is not uncommon to find an emitter on a hose next to a microsprayer, both of them operating simultaneously, with one of each for every tree. The emitter may have been used the first year of tree growth, and then the microsprayer was installed the second year. If there are different emitters throughout the field because of some random emitter replacement program, the ITRC program will not provide a precise estimate of system DU. A disclaimer is printed out on the summary page if this occurs. However, systems with this type of problem typically suffer from a wide range of problems related to poor design and management, so the precise DU value is not that important - the evaluators will have identified these other problems. 
Table 4. Cachuma RCD evaluation results (Cachuma RCD, 1994).

\begin{tabular}{lcc}
\hline & \multicolumn{2}{l}{ Number of fields in this DU range } \\
\cline { 2 - 3 } $\mathrm{DU}_{\text {lq }}$ range & Drip & Micro \\
\hline $.90-.97$ & 20 & 4 \\
$.80-.89$ & 17 & 18 \\
$.70-.79$ & 30 & 18 \\
$.60-.69$ & 11 & 12 \\
$.50-.59$ & 9 & 9 \\
$.40-.49$ & 5 & 7 \\
$.30-.39$ & 4 & 2 \\
$.20-.29$ & - & 3 \\
$.10-.19$ & 1 & 3 \\
$0.0-.09$ & & 1 \\
Total number of fields & 97 & 77 \\
Average DU & 0.75 & 0.65 \\
\hline
\end{tabular}

Field evaluation results with the ITRC evaluation procedures

\section{Cachuma RCD 1994}

The Cachuma Resource Conservation District (1994), located in Santa Maria, reported results of 97 drip system and 77 micro system evaluations. The average DUs for drip and micro systems were 0.74 and 0.65 , respectively. Table 4 shows more detailed results. The systems were typically on hilly topography.

\section{California mobile labs}

Hanson et al. (1996) reported on the results of 481 mobile laboratory evaluations of drip/micro irrigation systems using the ITRC evaluation program. These results (Table 5) did not include the Cachuma RCD results presented above.

\section{Cal Poly student teams}

In the summers of 1997-2004, ITRC received funding from the US Bureau of Reclamation's Mid-Pacific Region to train and supervise two-person student evaluation teams. Irrigation districts in California's San Joaquin and Sacramento Valleys (when combined, known as the "Central Valley") assisted the teams by contacting interested farmers. 
Table 5. Results from 481 California mobile lab field evaluations (Hanson et al., 1996).

\begin{tabular}{lcc}
\hline & \multicolumn{2}{c}{ Percent of fields in this DU range } \\
\cline { 2 - 3 } $\mathrm{DU}_{\mathrm{lq}}$ range & $\begin{array}{l}\text { Drip/micro for } \\
\text { permanent crops }\end{array}$ & $\begin{array}{l}\text { Drip for row crops } \\
\text { (typically tape systems) }\end{array}$ \\
\hline $.95-1.0$ & 2 & - \\
$.90-.949$ & 8 & 4 \\
$.85-.899$ & 13 & - \\
$.80-.849$ & 15 & 9 \\
$.75-.799$ & 16 & 4 \\
$.70-.749$ & 12 & 17 \\
$.65-.699$ & 11 & 17 \\
$.60-.649$ & 7 & 17 \\
$.55-.599$ & 6 & 13 \\
$.50-.549$ & 4 & - \\
Less than 0.50 & 7 & 23 \\
Total number of fields & 458 & 0.63 \\
Average $\mathrm{DU}$ & 0.73 &
\end{tabular}

The team members attend regular Cal Poly irrigation classes, plus a fiveday irrigation evaluation short course taught by ITRC every spring. The first three weeks, students must send all of their data, results, and anticipated recommendations to ITRC for review prior to submitting anything to the farmers. About three weeks of careful supervision are needed before the students become competent in conducting and interpreting evaluations. It has become very clear that a successful evaluation program requires excellent training, facilitating software, proper testing equipment, and a high level of technical support early in the program. Drip/micro irrigation systems are quite varied from field to field, and the drip/micro evaluation procedure has many subtleties that need to be understood by evaluators. Without the detailed review of the first three weeks, there would be significant errors in the recommendations and computed DU values. Because of this detailed training and review process, ITRC has a high degree of confidence in the results of the team evaluations.

A field evaluation (Figure 1) typically requires a full day by the student team. This includes time required to contact the farmer, conduct the evaluation, enter the field data into the computer, draw a sketch of the field showing where measurements were taken, develop recommendations, and finally review the results with the farmer.

A total of 329 evaluations of drip/micro systems were conducted by the student teams during the summers through 2003. Additional evaluations were 


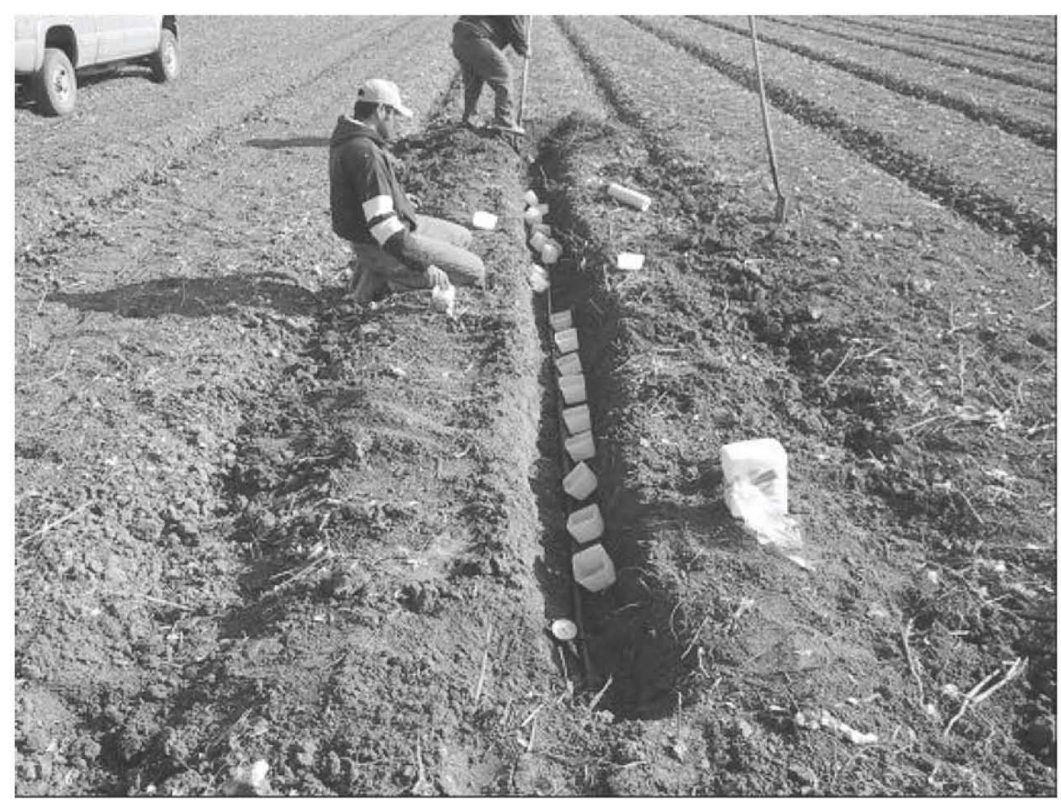

Figure 1. Evaluation of "other" causes of non-uniformity (plugging, manufacturing variation, aging, and wear) at one point in an SDI system for cotton. All the emitters are at the same pressure.

conducted on fields with furrow, border strip, and various sprinkler irrigation systems. Results of the drip/micro evaluations are found in Table 6 and Figure 2.

Figure 2 and Table 6 show that the average DU of the drip systems is higher $(0.86)$ than the average for the microspray systems $(0.81)$. This is probably due to three causes:

1. Many of the newer drip systems use excellent pressure compensating emitters.

2. It is not unusual for microspray systems to have excess wear due to the injection of abrasive, impure gypsum.

Table 6. Summary of ITRC Drip/Micro evaluation results.

\begin{tabular}{llll}
\hline Irrigation method & $\begin{array}{l}\text { \# of Fields } \\
\text { evaluated }\end{array}$ & $\begin{array}{l}\text { Average } \\
\mathrm{DU}_{\mathrm{lq}}\end{array}$ & $\begin{array}{l}\text { Coefficient of } \\
\text { variation of the DU values }\end{array}$ \\
\hline Drip & 133 & .86 & .127 \\
Microspray & 196 & .81 & .123 \\
Total or average & 329 & .83 & .12 \\
\hline
\end{tabular}




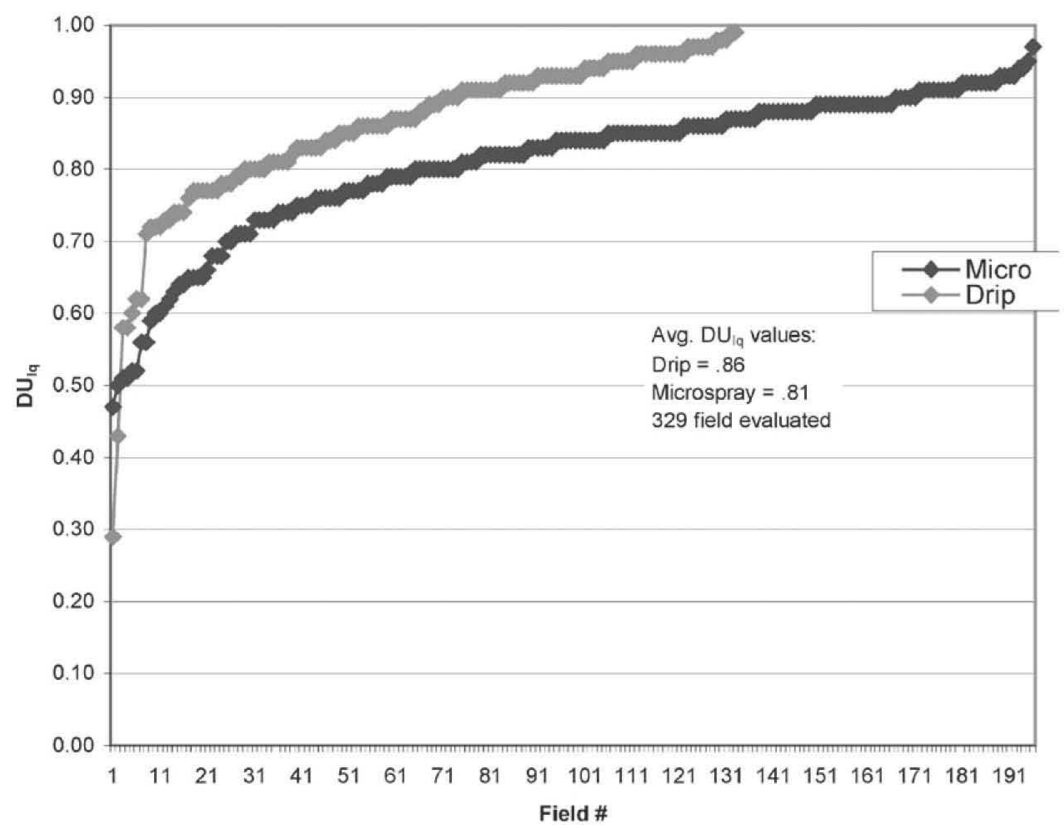

Figure 2. Results of 329 evaluations of drip/micro systems by Cal Poly ITRC students.

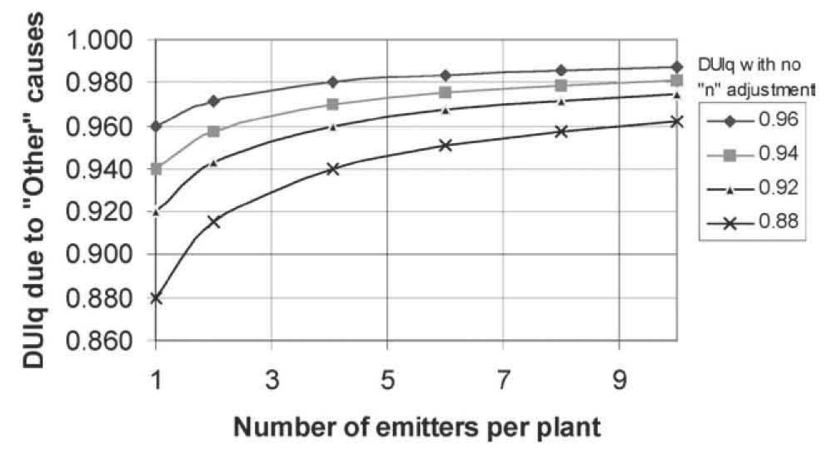

Figure 3. Effect of the number of emitters per tree on the final $\mathrm{DU}_{\text {Iqother. }}$.

3. Most systems with microsprayers only have one or two microsprayers per plant. Therefore, there is little or no averaging effect due to the number of emitters per plant in the $\mathrm{DU}_{\text {other }}$ computation, whereas with drip systems on trees there are often 6-12 emitters per plant. The impact on this adjustment for " $n$ " on the $\mathrm{DU}_{\text {other }}$ computation is seen in Figure 3. However, in vineyards there are typically one to two emitters/plant, and with row crop drip it is assumed that there is one emitter per plant. Therefore, for those crops there is also little or no average effect for drip systems-just as with microsprayers. 
The worst performances were seen with drip systems-perhaps because with microsprayers it is obvious when there is plugging, but not so with regular drip emitters. Also, buried drip systems can have extensive root intrusion problems. In any case, the data clearly show that it is possible to achieve very high uniformities in the field if both design and maintenance are good.

The average age of the systems was six years. Interestingly, there is no correlation between the age of the system and the DU (Figure 4). This was also noted by Hanson et al (1996). Another way to interpret this is that even a new system can have a high DU or a low DU-meaning that the customer should review the "Irrigation Consumer Bill of Rights" (Burt \& Styles 1999) prior to purchasing a system (downloadable at www.itrc.org). This will help ensure that the new system is of high quality. A second observation is that there are some 20-year-old drip/micro systems that still have good uniformity.

The ITRC evaluation procedure computes what percentage of the nonuniformity is due to each component. The relative importance of the individual components of non-uniformity are almost identical for both drip and microspray systems. The categories of "other" (which includes plugging, wear, and manufacturing variation) and "pressure differences between emitters" have almost equal importance (Figure 5).

Although unequal drainage is a serious problem on systems with steep topography and short set durations, overall it ranked very low (1.6\%) in importance. Likewise, non-uniformity due to "application rate" (also called "uneven spacing") is very important on some fields, but overall it was only responsible for about $2.5 \%$ of the measured non-uniformity.

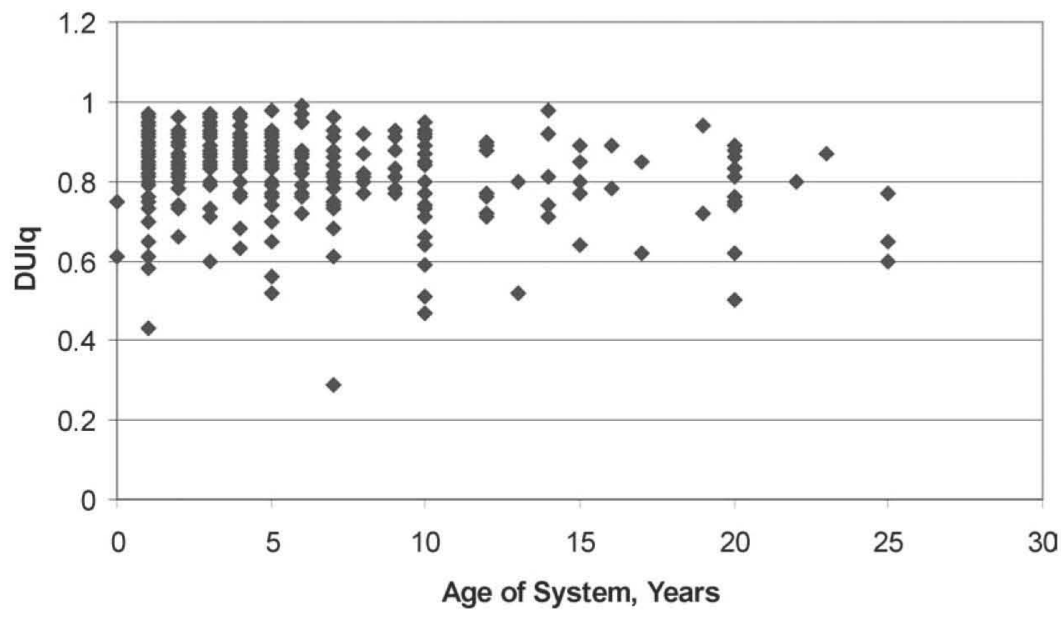

Figure 4. There was no relationship between the measured DU and the system age. 

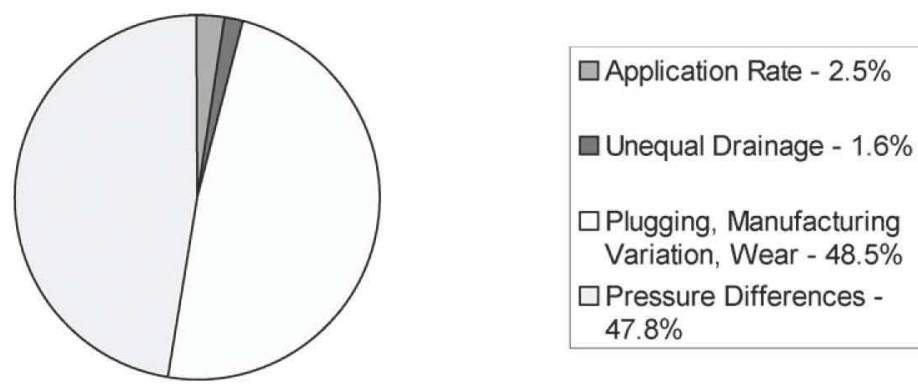

Figure 5. Pressure differences and "other" causes are almost equally important factors of non-uniformity for both drip and microspray.

\section{Conclusion}

The Cal Poly ITRC drip/micro evaluation program estimates global, or system, $\mathrm{DU}_{\mathrm{lq}}$ by combining the component $\mathrm{DU}_{\mathrm{lq}}$ values of (i) pressure differences, (ii) "other" factors including plugging, wear, material aging, and manufacturing variation, (iii) uneven spacing, and (iv) unequal drainage. A complete field evaluation requires about two person-days to organize, conduct, and summarize. The program has been widely used in the western US for 15 years, and provides standardized procedures, definitions, and computations.

It appears that the DU of drip/micro systems is improving with time. Although the available results are from different geographical areas within California, it is interesting to note that the pre-1996 results that were summarized by Cachuma RCD (1994) and Hanson et al. (1996) had average drip $\mathrm{DU}_{\mathrm{lq}}$ values of $0.73-0.75$, and average microsprayer $\mathrm{DU}_{\mathrm{lq}}$ values of $0.63-$ 0.65 . However, the more recent Cal Poly student evaluations showed average drip $\mathrm{DU}_{\mathrm{lq}}$ values of 0.85 , and average microsprayer $\mathrm{DU}_{\mathrm{lq}}$ values of 0.80 considerably higher than the earlier values. The author believes that this is a true trend, which reflects the improved design techniques by irrigation dealers, as well as the availability of better emitters, filters, and chemical injection techniques.

Results show that pressure differences and "other" causes are equally important factors of non-uniformity. With proper maintenance, "other" causes should be limited to manufacturing variation with a new system (and this only contributes to a relatively slight decline in DU). Therefore, it is reasonable to conclude that DU values decrease with time. This statement is not inconsistent with the observation that there is no correlation between system age and DU. The first observation compares a system against itself over time; the second just compares measured DU values of independent systems against the systems' ages. What is certainly apparent is that, whether one starts with a good or bad DU, it is possible to maintain a fairly high DU over many years. 


\section{Acknowledgments}

Funding for this work was provided by the mid-Pacific region of the US Bureau of Reclamation.

\section{References}

Bliesner, R.D. 1977. Field evaluation of trickle irrigation efficiency. Proceedings of the ASCE I\& D Specialty Conference on Water Management for Irrigation and Drainage (pp 382393), Reno, NV.

Bralts, V.F. \& Kesner C.D. 1983. Drip irrigation field uniformity estimation. Transactions of ASAE 26(5): 1369-1374.

Burt, C.M., Clemmens, A.J., Strelkoff, T.S., Solomon, K.H., Bliesner, R.D., Hardy, L.A., Howell, T.A. \& Eisenhauer, D.E. 1997. Irrigation performance measures-efficiency and uniformity. Journal of Irrigation and Drainage Engineering ASCE 123(6): 423-442.

Burt, C.M., Walker, R.E. \& Styles, S.W. 1985. Irrigation System Evaluation Manual. Department of Agricultural Engineering, California Polytechnic State University, San Luis Obispo, CA.

Burt, C.M. \& Styles, S.W. 1999. Drip and Micro Irrigation for Trees, Vines, and Row Crops (p. 292). Irrigation Training and Research Center, California Polytechnic State University, San Luis Obispo, California.

Cachuma Resource Conservation District. 1994. Final Report. Irrigation Water Management Program Santa Barbara and San Luis Obispo Counties. Cachuma RCD. Santa Maria, California.

Clemmens, A.J. \& Solomon, K.H. 1997. Estimation of global irrigation distribution uniformity. Journal of Irrigation and Drainage Engineering ASCE 123(6): 454-461.

Dahlgren, K.M. 1987. Estimating Emission Uniformity in Drip Irrigation. M.S. Thesis, Agricultural Engineering Department California Polytechnic State University, San Luis Obispo, California.

Fry, R.A. 1985. Trickle system evaluation findings in the San Joaquin Valley, California. Proceedings of the Third International Drip/Trickle Irrigation Congress Held in Fresno (pp. 288-293, Vol. 10-85(I)), ASAE Publication, California.

Handley, D., Vaux, Jr. H.J. \& Pickering, N. 1983. Evaluating low-volume irrigation systems for emission uniformity. California Agriculture January-February: 10-12.

Hanson, B., Bowers, W., Davidoff, B., Kasapligil, D., Carvajal A. \& Bendixen, W. 1996. Field performance of microirrigation systems. Proceedings of the Fifth International Microirrigation Congress (pp. 769-774), Orlando, Florida.

Karmeli, D. \& Keller, J. 1974. Trickle Irrigation Design. Rain Bird Sprinkler Manufacturing Corp., Glendora, California.

Lamm, F.R., Storlie, C.A. \& Pitts, D.J. 1997. Revision of EP-458: Field evaluation of microirrigation systems. ASAE Paper 972070, p. 20.

Merriam, J.L., Keller, J. \& Alfaro, J.F. 1973. Irrigation Systems Evaluation and Improvement. Agricultural and Irrigation Engineering Department, Utah State University, Logan, UT.

Merriam, J.L. \& Keller, J. 1978. Farm Irrigation System Evaluation: A Guide for Management (p. 271). Agricultural and Irrigation Engineering Department, Utah State University, Logan, UT. 
Nakayama, F.S. \& Bucks, D.A. 1981. Emitter clogging effects on trickle irrigation Uniformity. Transactions of ASAE 24(1): 77-80.

Nakayama, F.S., Bucks, D.A. \& Clemmens, A.J. 1979. Assessing trickle emitter application uniformity. ASAE Paper, pp. 78-2017.

Parchomchuk, P. 1976. Temperature effects on emitter discharge rates. Transactions of ASAE 19: 690-692.

Raphael, F. 1993. A Hydraulic Evaluation of Permanent Subsurface Drip Irrigation Laterals. M.S. Thesis, Department of Agricultural Engineering, California Polytechnic State University, San Luis Obispo, California.

Solomon, K. \& Keller, J. 1978. Trickle irrigation uniformity and efficiency. Journal of Irrigation and Drainage Engineering ASCE 104(IR3): 293-306.

USDA. 1956. Methods for Evaluating Irrigation Systems. Agriculture Handbook 82. Soil Conservation Service, U.S. Department of Agriculture, p. 24. 